\title{
Fetal Anal Incontinence Evaluated by Amniotic Fluid Digestive Enzyme Assay in Myelomeningocele Spina Bifida
}

\author{
HANA TALABANI, SOPHIE DREUX, DOMINIQUE LUTON, BRIGITTE SIMON-BOUY, \\ BERNARD LE FIBLEC, JEAN-YVES COL, JEAN GUIBOURDENCHE, \\ JEAN-FRANÇOIS OURY, AND FRANÇOISE MULLER
}

Biochimie Hormonale [H.T., S.D., J.G., F.M.] and Gynécologie-Obstétrique [D.L., J.-F.O.], Hôpital Robert Debré, 75019, Paris; SESEP [B.S.-B.], Université de Versailles Saint Quentin, 78000, Versailles; Gynécologie-Obstétrique [B.L.F.], Centre Hospitalier, 22023, Saint-Brieuc; Gynécologie-obstétrique J.-Y.C.], Hôpital Flaubert, 76083, Le Havre; and Université Paris Ile de France Ouest [F.M.], Paris,

France

\section{ABSTRACT}

The goals of this study were to determine whether anal sphincter dysfunction in spina bifida develops during fetal life or after birth and whether it reflects the severity of spina bifida and therefore can be used as a criterion to select the cases that could benefit from in utero surgery. Total protein and digestive enzyme activities [ $\gamma$-glutamyl transpeptidase (GGTP), aminopeptidase M (AMP), and alkaline phosphatase isoenzymes including the intestinal form (iALP)] were assayed retrospectively in amniotic fluid from 80 myelomeningocele spina bifida cases without unrelated associated malformation (gestational age 14-33 wk). A normal enzyme activity profile was observed in 46 of the 80 cases. Two abnormal profiles were observed: 1) bilious vomiting, characterized by abnormally high GGTP and AMP activities but normal iALP, and 2) digestive enzyme leakage, characterized by abnormally high activities of GGTP, AMP, and iALP, typical of anal incontinence. No relation was observed between these en- zyme activity profiles and the different secondary signs of spina bifida or the level of the damage. In conclusion, anal sphincter dysfunction in spina bifida revealed by amniotic fluid digestive enzyme activities occurred before 24 wk in fetal life in $28.7 \%$ of cases. This criterion may be indicative of the severity of spina bifida and therefore perhaps could be used to select cases that are suited to in utero surgery. It could also be used to establish the potential benefit of this surgery in fecal incontinence. (Pediatr Res 58: 766-770, 2005)

AMP, aminopeptidase M

GGTP, $\gamma$-glutamyl transpeptidase

iALP, intestinal isoenzyme of alkaline phosphatase

MoM, multiple of median
Spina bifida aperta (myelomeningocele) affects 1 of 2000 infants worldwide. The cause of spina bifida is unknown and probably multifactorial (1). The most generally accepted pathogenetic mechanism is a primary disorder of neurulation with failure of the embryologic neural plate to close (2). It is becoming less common because of prevention by vitamin supplementation (3) and because it can be detected early in gestation by maternal serum $\alpha$-fetoprotein assay (4) and ultrasonography screening, confirmed by amniotic fluid cholinesterase electrophoresis $(5,6)$. This nonlethal spinal cord malformation leads to lifelong and devastating physical disabilities,

Received September 28, 2004; accepted January 26, 2005.

Correspondence: Françoise Muller, M.D., Ph.D., Biochimie Hormonale, Hôpital Robert Debré, 48 Boulevard Sérurier, 75935 Paris Cedex 19; e-mail: francoise.muller@ rdb.ap-hop-paris.fr.

DOI: 10.1203/01.PDR.0000180539.40399.93 including paraplegia, hydrocephalus, skeletal deformations, sexual dysfunction, and urinary and fecal incontinence (7). In addition, the children often show impaired mental development.

Although it has been assumed that the spinal cord is intrinsically defective, recent studies suggest that neurologic impairment after birth may be due to exposure of the spinal cord in utero. It has been hypothesized that the neurologic deficit associated with open spina bifida is not caused directly by the primary defect but rather is due to chronic mechanical and chemical trauma. The resulting studies strongly suggested that amniotic fluid is toxic to the spinal cord, especially later in gestation, when it consists largely of fetal urine (8-10). Therefore, this suggests that secondary neural tissue destruction during pregnancy is primarily responsible for the functional 
loss and that timely in utero repair of open spina bifida might rescue neurologic function.

The promise of fetal intervention in the treatment of spina bifida is to correct the structural defect at a time when significant neuronal damage either has not yet occurred or still has the potential to be reversed. Thus, the rationale for in utero myelomeningocele surgery was born. In a comparative study based on 104 fetuses with in utero therapy and 189 infants with conventional postnatal surgery, Tulipan et al. (11) analyzed the need for cerebrospinal fluid shunting at 1 y (54.8 versus $85.7 \%$, respectively). A significant difference was observed when the defect occurred lower than lumbar vertebra 2. Gestational age at surgery is crucial because the benefit is observed only when in utero surgery is performed before $25 \mathrm{wk}$. However, in this study and initial reports (12-14), although reduced hindbrain herniation was observed, no improvement was noted in motor defects or in sphincter anomalies.

In the present study, we investigated fetal anal incontinence, one of the major consequences of spina bifida, in 80 cases of myelomeningocele spina bifida. The mechanisms underlying fetal anal continence depend on the stage of development of the intestinal tract. These stages are opening of the pharyngeal membrane at $\sim 9 \mathrm{wk}$, swallowing, maturation of intestinal microvilli with secretion of digestive enzymes, and opening of the anal membrane at $\sim 12 \mathrm{wk}$. Amniotic fluid digestive enzyme levels during gestation reflect these different stages (15). Before $12-13 \mathrm{wk}$, no enzymes are present, but when the anal membrane opens, accumulated digestive secretions flow into the amniotic fluid. At $14-18 \mathrm{wk}$, a balance between swallowing and anal elimination develops. Thereafter, digestive secretions decrease progressively and at 22-24 wk are absent from the amniotic fluid. Assay of digestive enzymes in amniotic fluid is helpful in diagnosing various gastrointestinal diseases: digestive obstruction before 22-24 wk and regurgitation of bile as a result of upper small intestine atresia and anal leakage after 22-24 wk (16).

The goals of this study were to determine whether 1 ) anal sphincter dysfunction in spina bifida develops during fetal life or after birth;2) it is indicative of the severity of spina bifida and therefore can be used as a criterion to select the most severe cases that could benefit from in utero surgery; 3) spinal cord injury differs between cases with digestive secretions present throughout fetal life (early anal incontinence) and cases with anal continence; and 4) anal continence can be used as a marker of the potential benefit of in utero surgery in analyzing whether anal incontinence present during fetal life disappears during infancy after in utero surgery.

\section{METHODS}

During the period 2000-2003, 4195 amniotic fluid samples were sent from 24 institutions to our laboratory for neural tube defect screening on the basis of cholinesterase electrophoresis. In accordance with French law, consent for amniotic fluid sampling and laboratory testing was obtained from each patient. Of the 4195 samples, 102 presented two acetylcholinesterase bands and therefore were of the myelomeningocele type, 83 spina bifida and 19 anencephaly $(5,6)$. Of the 83 cases of spina bifida, fetal karyotyping was normal in 80 and abnormal in three (trisomy 18, trisomy 13, and unbalanced translocation 6 to 10). The 80 spina bifida cases without associated malformation constituted the database of this study. Gestational age at amniocentesis ranged from 14 to $33 \mathrm{wk}$ of amenorrhea ( 24 before $20 \mathrm{wk}, 43$ between 20 and $24 \mathrm{wk}$, and 13 after). In France, all patients undergo three ultrasound examinations, at 11,22 , and 33 wk. The outcome of pregnancy is known in all cases. Pregnancy was terminated in 78 cases at the request of the parents in accordance with French law, in utero death occurred in one case, and neonatal death occurred in one case. A twin pregnancy was observed in three cases (one twin affected), and a selective termination of pregnancy was performed. Anatomic examination was refused by the parents in five cases and performed in all others. We used ultrasound findings and/or anatomic observations to identify any secondary anomalies such as ventriculomegaly, Arnold Chiari malformation, clubbed feet, and leg movements and to locate neural tube defects. Spina bifida was dorsolumbar or lumbar (10 cases), lumbosacral (44 cases), sacral (21 cases), or unknown (five cases).

The 19 anencephaly cases were taken as controls. Ninety-five cases of ventricular dilation over $10 \mathrm{~mm}$, with normal cholinesterase electrophoresis, constituted a second control population.

Amniotic fluid was stored at $-20^{\circ} \mathrm{C}$ and analyzed retrospectively. Total protein and amniotic fluid digestive enzyme activities were assayed using an autoanalyzer (Hitachi 911; Roche Diagnostics, Mannheim, Germany): $\gamma$-glutamyl transpeptidase (GGTP), aminopeptidase M (AMP), and alkaline phosphatase isoenzymes including the intestinal form (iALP). Normal values (1st, 50th, and 99th percentiles) were established for each week (between 7 and 37) using $>1000$ cases. Each value was expressed in multiple of median (MoM), by dividing the measured value by the median value (50th percentile) observed in control patients for the same gestational age. We checked that the first percentile corresponds to $0.5 \mathrm{MoM}$ and the 99th percentile to $2.5 \mathrm{MoM}$ Between-group comparisons were made by means of the $\chi^{2}$ test.

\section{RESULTS}

Normal amniotic fluid digestive enzyme activities are related to the physiologic maturation of the fetal digestive tract. Enzymes are absent until 13-14 wk of amenorrhea. Swallowed amniotic fluid then carries enzymes that are secreted into the digestive tract through the anal sphincter into the amniotic cavity, resulting in high but physiologic amniotic fluid activities of GGTP, AMP, and iALP. After 18 wk, maturation of the anal sphincter and accumulation of meconium in the cecum impair flow into the amniotic fluid, resulting in sharp decreases of these enzymes in the amniotic fluid.

Amniotic fluid digestive enzyme activities in spina bifida. A normal profile was observed in $46(57.5 \%)$ of the 80 cases with myelomeningocele spina bifida. The profile of digestive obstruction characterized by abnormally low $(<1$ st percentile) activities of all three digestives enzymes was not observed. Two abnormal profiles were observed: 1 ) the profile of bilious vomiting (six cases; $7.5 \%$ ), characterized by abnormally high ( $>99$ th percentile) GGTP and AMP activities but normal iALP, and 2) the profile of digestive enzyme leakage ( 28 cases; $35 \%$ ), characterized by abnormally high ( $>99$ th percentile) activities of all three digestive enzymes. This profile is typical of anal incontinence. No difference was observed between before $24 \mathrm{wk}$ and after $\left(\chi^{2}=0.9\right.$, NS; Table 1 and Fig. 1).

Amniotic fluid digestive enzyme profiles and secondary signs of spina bifida. No relation $\left(\chi^{2}, N S\right)$ was observed between various secondary cerebral signs of spina bifida (ven-

Table 1. Amniotic fluid digestive enzyme profile and gestational age in 80 cases of spina bifida

\begin{tabular}{lccl}
\hline \multicolumn{1}{c}{$\begin{array}{c}\text { Amniotic fluid digestive } \\
\text { enzyme profile }\end{array}$} & $\begin{array}{c}<20 \text { weeks } \\
(\mathrm{n}=24)\end{array}$ & $\begin{array}{c}20-24 \text { weeks } \\
(\mathrm{n}=43)\end{array}$ & $\begin{array}{c}25-33 \text { weeks } \\
(\mathrm{n}=13)\end{array}$ \\
\hline Normal $(\mathrm{n}=46 ; 57.5 \%)$ & $23(96 \%)$ & $15(35 \%)$ & $8(61.5 \%)$ \\
Bilious vomiting $(\mathrm{n}=6 ; 7.5 \%)$ & $1(4 \%)$ & $5(11.6 \%)$ & 0 \\
Anal leakage $(\mathrm{n}=28 ; 35 \%)$ & 0 & $23(53.4 \%)$ & $5(38.5 \%)$ \\
\hline
\end{tabular}

No significant differences between before 24 weeks and after (Chi square = $0.9)$. 


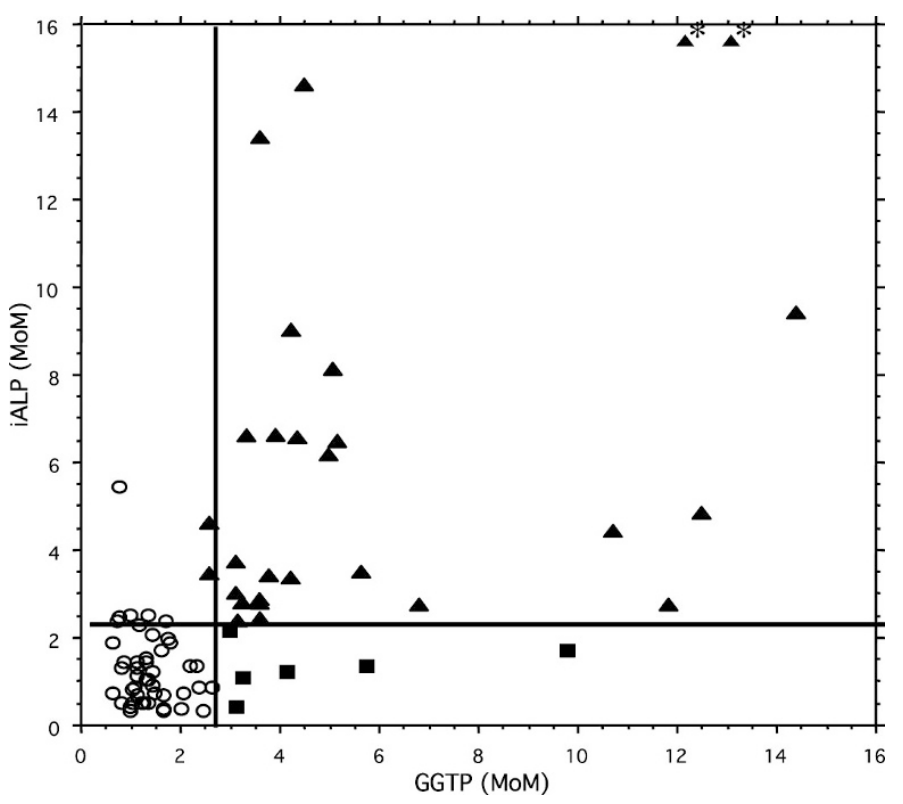

Figure 1. Relation between amniotic fluid GGTP and iALP in the three digestive obstruction profiles (normal $\bigcirc$, bilious vomiting $\mathbf{\square}$, and anal leakage $\Delta)$ in 80 patients with myelomeningocele. All values are expressed in MoM. Cutoff values $(2.5 \mathrm{MoM})$ are shown by vertical and horizontal lines. *iALP value $>16 \mathrm{MoM}$

triculomegaly, Arnold Chiari) or secondary leg paralysis and these different amniotic fluid digestive enzyme activity profiles (Table 2).

Amniotic fluid digestive enzyme profiles and localization of spina bifida. Evidence of intrauterine fecal incontinence did not correlate with the level of spinal injury ( $\chi^{2}$ NS; Table 3 ).

Amniotic fluid digestive enzyme profiles in anencephaly. A normal amniotic fluid digestive enzyme profile was observed in the 19 cases.

Amniotic fluid digestive enzyme profiles in ventricular dilation. A normal amniotic fluid digestive enzyme profile was observed in 90 cases, a bilious vomiting profile in two, and anal leakage in three.

\section{DISCUSSION}

We have previously demonstrated that amniotic fluid digestive enzyme levels during gestation reflect the different stages of development of the fetal intestinal tract $(15,16)$. The first stage occurs at 7-8 wk with intestinal microvilli maturation, which leads to gastrointestinal secretions. Then anal sphincter maturation occurs in several stages, the first being perforation

Table 2. Amniotic fluid enzyme profiles and secondary malformations detected at ultrasound scan (documented in 75 of the 80 cases for cerebral signs and in 70 of 80 for leg signs)

\begin{tabular}{lccc}
\hline & $\begin{array}{c}\text { Normal profile } \\
(\mathrm{n}=56)\end{array}$ & $\begin{array}{c}\text { Bilious vomiting } \\
(\mathrm{n}=6)\end{array}$ & $\begin{array}{c}\text { Anal leakage } \\
(\mathrm{n}=18)\end{array}$ \\
\hline Cerebral signs (74/75) & $50(67 \%)$ & $6(8 \%)$ & $18(25 \%)$ \\
No cerebral signs $(1 / 75)$ & 1 & 0 & 0 \\
Leg anomalies $(35 / 70)$ & $23(66 \%)$ & $3(9 \%)$ & $9(25 \%)$ \\
No leg anomalies $(35 / 70)$ & $25(71 \%)$ & $2(6 \%)$ & $8(23 \%)$ \\
\hline
\end{tabular}

No significant relation between secondary associated signs of spina bifida and digestive enzymes profiles (Chi square NS).
Table 3. Amniotic fluid digestive enzyme profiles and localization of myelomeningocele spina bifida (80 cases)

\begin{tabular}{lcccc}
\hline & $\begin{array}{c}\text { Dorsolumbar } \\
\text { or lumbar } \\
(\mathrm{n}=10)\end{array}$ & $\begin{array}{c}\text { Lumbosacral } \\
(\mathrm{n}=44)\end{array}$ & $\begin{array}{c}\text { Sacral } \\
(\mathrm{n}=21)\end{array}$ & $\begin{array}{c}\text { Unknown } \\
(\mathrm{n}=5)\end{array}$ \\
\hline Normal profile $(\mathrm{n}=46)$ & $7(70 \%)$ & $22(50 \%)$ & $12(57 \%)$ & 5 \\
Bilious vomiting $(\mathrm{n}=6)$ & 0 & $5(12 \%)$ & $1(5 \%)$ & 0 \\
Anal leakage $(\mathrm{n}=28)$ & $3(30 \%)$ & $17(38 \%)$ & $8(38 \%)$ & 0 \\
\hline
\end{tabular}

No significant differences (Chi square NS).

of the anal membrane at $12 \mathrm{wk}$, which coincides with the massive arrival of digestive enzymes in the amniotic fluid. The second is the progressive development of the three anal sphincter muscles (external, superficial, and deep) from 15 wk to $28-30$ wk $(17,18)$. From 12 to 22 wk, digestive enzymes are present in the amniotic fluid, reaching a maximum at 16-17 wk, and then progressively decreasing to residual activities by 22-24 wk. During the period 15-27 wk, the three anal sphincter muscles progressively mature, thus possibly explaining the gradual anal passage closure leading to the absence of digestive secretions and meconium in amniotic fluid. The absence of amniotic fluid digestive enzymes in anal atresia confirms the relation between amniotic fluid digestive enzyme levels and anal passage.

In the present study, we assayed amniotic fluid digestive enzymes in 80 cases of myelomeningocele spina bifida. We observed a normal profile in $46(57.5 \%)$ of 80 cases, bilious vomiting in six (7.5\%), and digestive enzyme anal loss in 28 (35\%). We postulate that abnormally high digestive enzymes in the amniotic fluid reflect anal incontinence as a result of the spinal lesions observed in myelomeningocele. This assertion is supported by our previous studies of amniotic fluid digestive enzymes and fetal tissue at different stages of development and in pregnancies with fetal digestive tract anomalies $(15,16)$. The enzyme profile characterized by the abnormal presence of all digestive secretions in the amniotic fluid after 20 wk reflects anal incontinence whatever the mechanism. It is seen, for instance, in high anal atresia associated with urodigestive fistula, because secretions flow through the urinary tract. It is also observed in microcolon-megabladder hypoperistalsis syndrome, in chloride diarrhea, in cytomegalovirus infection, and in fetal distress of whatever cause (16). This profile is very rare in normal pregnancy, $<0.1 \%$ of cases. Therefore, the presence of this sign in myelomeningocele spina bifida can be related to anal incontinence as a result of defective anal innervation. This notion is supported by a study of Shapiro et al. (19), in which seven human fetuses ( $20 \mathrm{wk}$ of gestation) with myelomeningocele presented decreased innervation and defective smooth muscle development in the lower genitourinary and gastrointestinal tracts. However, we are unable to explain why only $35 \%$ and not $100 \%$ of our cases presented anal incontinence.

The profile of anal incontinence was observed as early as 20-24 wk. This finding demonstrates that anal incontinence is a primary consequence of myelomeningocele and not a secondary complication as a result of spinal exposure to amniotic fluid. This perhaps can explain why anal incontinence is not corrected by fetal surgery in humans. Because all of our 
pregnancies were terminated, it was not possible to establish a relation between prenatal anal incontinence and postnatal sphincter function and particularly whether cases with no anal incontinence during fetal life present anal sphincter impairment after birth. Unfortunately, posttermination fetal histopathology reports were not detailed enough to allow study of the relation between the abnormally high levels of digestive enzymes in amniotic fluid and the degree of inflammation, necrosis, and injury of neural tissue. The absence of anal incontinence in anencephaly observed here confirms the major role of a peripheral rather than a central origin of anal sphincter control.

The incidence of ventricular shunting as a function of spinal level of lesion (thoracic $>$ lumbar $>$ sacral) was studied postnatally by Rintoul et al. (20) but not sphincter function. We observed no relation between fetal anal incontinence and the location of the spina bifida. In the lumbosacral defect, which represents $59 \%$ of our cases, anal incontinence was present in $38.6 \%$ of cases, a percentage not significantly different from that observed in the sacral defect $(38 \%)$. Secondary leg paralysis (absence of movements and/or club feet) was observed in $37(51 \%)$ of the 72 documented cases, and no relation was observed between leg paralysis and anal incontinence (24\% with and $23 \%$ without).

Bilious vomiting was observed in six $(7.5 \%)$ of the 80 cases. It could be hypothesized that the bilious vomiting center in the brain was compressed as a result of ventricular dilation associated with spina bifida. However, because this profile was not observed at a high frequency $(2 \%)$ in isolated ventricular dilation, this hypothesis is unsustainable. In addition, no special cerebral signs were noted in the spina bifida cases with in utero bilious vomiting, and we have no explanation for this finding.

Experimental studies in animal models have sought to determine whether fetal surgery to repair myelomeningocele allows normal development of anal sphincter muscles. In fetal sheep, Meuli et al. (21) observed no signs of incontinence after in utero repair of experimental myelomeningocele. In an experimental study, Yoshizawa et al. (22) analyzed histologically external and internal anal sphincter muscles. They concluded that fetal surgery for repair of myelomeningocele allows normal development of anal sphincter muscles. In humans, the first in utero surgical repair of myelomeningocele was reported in $1998(23,24)$. This preliminary experience demonstrated that prenatal surgery reduces the need for postnatal ventriculoperitoneal shunting; however, unlike in animal models, anal and urinary sphincter function was not corrected (14). Therefore, we suggest that amniotic fluid enzyme activities could perhaps help to select cases that would benefit from in utero surgery. If early fetal in utero surgery is performed in cases with early anal incontinence, then it could be verified at birth whether anal incontinence has been corrected.

Because of the severity of myelomeningocele spina bifida, most parents opt for termination of pregnancy. However, prenatal treatment may be a viable alternative. Invasive treatment, such as in utero surgery, may be justified by the high incidence of spina bifida and also by the fact that termination of pregnancy is not allowed after $24 \mathrm{wk}$ in most countries. However, the fetal surgery results observed are not in full accordance with those recorded in animal models.
These discordances may stem from the heterogeneity of cases in human fetuses compared with the standardized lesions created in animal experimentation. This is why our observation of three populations of spina bifida before 24 wk, one with normal amniotic fluid digestive enzymes, one with bile duct secretions, and the third with anal leakage of digestive secretions, may allow analysis of the benefit of in utero surgery in each of these three populations, rather than in all three taken together.

\section{CONCLUSION}

In this study, we demonstrated that anal sphincter dysfunction in spina bifida occurred early in fetal life in $28.7 \%$ of cases. This criterion may be indicative of the severity of spina bifida and therefore perhaps could be used to select those severe cases that could benefit from in utero surgery. Furthermore, it will be interesting to study whether the amniotic fluid toxicity for the spinal cord differs between cases with digestive secretions present throughout fetal life (early fecal incontinence) and cases with normal anal sphincter muscle function. Finally, anal continence could be a marker of the potential benefit of in utero surgery. For this, it will be necessary to establish whether fecal incontinence present during fetal life disappears during infancy after in utero surgery.

\section{REFERENCES}

1. Campbell LR, Dayton DH, Sohal GS 1986 A review of human and animal studies on the etiology of neural tube defects. Teratology 34:171-187

2. Copp AJ, Brook FA, Estibeiro JP, Shum AS, Cockroft DL 1990 The embryonic development of mammalian neural tube defects. Prog Neurobiol 35:363-403

3. MCR Vitamin Study Research Group 1991 Prevention of neural tube defects: results of the Medical Research Council Vitamin Study. Lancet 338:131-137

4. Wald NJ, Hackshaw A, Stone R, Densem J 1993 Serum alpha-fetoprotein and neural tube defects in the first trimester of pregnancy. MCR Vitamin Study Research Group. Prenat Diagn 11:1047-1050

5. Seller MJ, Cole KJ 1980 Polyacrylamide gel electrophoresis of amniotic fluid cholinesterases: good prenatal test for neural tube defects. Br J Obstet Gynaecol 87:1103-1108

6. Wald N, Cuckle H, Nanchahal K 1989 Amniotic fluid acetylcholinesterase measurement in the prenatal diagnosis of open neural tube defects. Second report of the Collaborative Acetylcholinesterase Study. Prenat Diagn 9:813-829

7. Copp AJ 1993 Neural tube defects. Trends Neurosci 16:381-383

8. Heffez DS, Aryanpur J, Hutchins GM, Freeman JM 1990 The paralysis associated with myelomeningocele: clinical and experimental data implicating a preventable spinal cord injury. Neurosurgery 26:987-992

9. Drewek MJ, Bruner JP, Whetsell WO, Tulipan N 1997 Quantitative analysis of the toxicity of human amniotic fluid to cultured rat spinal cord. Pediatr Neurosurg 27:190-193

10. Walsh DS, Adzick NS, Sutton IN, Johnson MP 2001 The rationale for in utero repair of myelomeningocele. Fetal Diagn Ther 16:312-322

11. Tulipan N, Sutton LN, Bruner JP, Cohen BM, Johnson M, Adzick NS 2003 The effect of intrauterine myelomeningocele repair on the incidence of shunt-dependent hydrocephalus. Pediatr Neurosurg 38:27-33

12. Bruner JP, Tulipan N, Paschall RI, Boehm FH, Walsh WF, Silva SR, HernanzSchulman Lowe LH, Reed GW 1999 Fetal surgery for myelomeningocele and the incidence of shunt-dependent hydrocephalus. JAMA 282:1819-1825

13. Sutton LN, Adzick NS, Bilaniuk LT, Jonhson MP, Crombleholme TM, Flake AW 1999 Improvement in hindbrain herniation demonstrated by serial fetal magnetic resonance imaging following fetal surgery for myelomeningocele. JAMA 282:1826-1931

14. Holmes NM, Nguyen HT, Harrison MR, Farmer DL, Baskin LS 2001 Fetal intervention for myelomeningocele: effect on postnatal bladder function. J Urol 166:2383-2386 
15. Muller F, Oury JF, Dumez Y, Boué J, Boué A 1988 Microvillar enzyme assays in amniotic fluid and fetal tissue at different stages of development. Prenat Diagn 8:189-198

16. Muller F, Dommergues M, Ville Y, Lewin F, Delvalez-Morichon N, Nihoul-Fekete C, Bargy F, Dumez Y, Boue A 1994 Amniotic fluid digestive enzymes: diagnostic value in fetal gastrointestinal obstructions. Prenat Diagn 14:973-979

17. Levi AC, Borghi F, Garavoglia M 1991 Development of the anal canal muscles. Dis Colon Rectum 34:262-266

18. Bourdelat D, Muller F, Droulle P, Barbet JP 2001 Anatomic and sonographica studies on the development of fecal continence and sphincter development in human fetuses. Eur J Pediatr Surg 11:124-130

19. Shapiro E, Seller MJ, Lepor H, Kalousek DK, Hutchins GM, Perlman EJ, Meuli M 1998 Altered smooth muscle development and innervation in the lower genitourinary and gastrointestinal tract of the male human fetus with myelomeningocele. J Urol 160:1047-1053
20. Rintoul NE, Sutton LN, Hubbard AM, Cohen B, Melchionni J, Pasquariello PS, Adzick NS 2002 A new look at myelomeningoceles: functional level, vertebral level, shunting, and the implications for fetal intervention. Pediatrics 109:409-413

21. Meuli M, Meuli-Simmen C, Hutchins GM, Yingling CD, Hoffman KM, Harrison MR Adzick NS In utero surgery rescues neurological function at birth in sheep with spina bifida. Nat Med 1:342-347, 1995

22. Yoshizawa J, Sbragia L, Paek BW, Sydorak RM, Yamazaki Y, Harrison MR, Farmer DL 2003 Fetal surgery for repair of myelomeningocele allows normal development of the rectum in sheep. Pediatr Surg Int 19:162-166

23. Tulipan N, Bruner JP 1998 Myelomeningocele repair in utero: a report of three cases Pediatr Neurosurg 28:177-180

24. Adzick NS, Sutton LN, Crombleholme TM, Flake AW 1998 Successful fetal surgery for spina bifida. Lancet 352:1675-1676 